\title{
Product Market Integration and Environmental Policy Coordination in An International Duopoly
}

\section{ODD RUNE STRAUME}

Department of Economics and Stein Rokkan Centre for Social Studies, University of Bergen, Herman Foss gate 6, N-5007 Bergen, Norway (E-mail: odd.straume@econ.uib.no)

Accepted 30 January 2006

Abstract. We analyse the effect of product market integration on environmental policy incentives in an international duopoly, where national policy makers act strategically. If traditional trade policy instruments are not available, environmental policies will typically be determined by the interaction of conflicting policy incentives. Contrary to popular belief, we find that international product market integration, in this particular setting, might reduce the need for transnational policy coordination, both from a purely environmental and from a social welfare perspective.

Key words: product market integration, strategic environmental policy, policy coordination

JEL classification: F12, F15, F18, H23

\section{Introduction}

One of the most important features of the ongoing process of globalisation is the increased integration of national (or regional) product markets. Elimination of trade barriers through bilateral or multilateral free trade agreements are accompanied by reductions of non-tariff trade costs, such as improved infrastructure and reduced bureaucratic barriers to trade. Reduction of non-tariff trade costs is arguably the more important force in the current process of international economic integration, due to the widespread establishment of free trade areas such as the European Economic Area (EEA), the North American Free Trade Agreement (NAFTA) and the Asian Free Trade Area (AFTA). A recent example of an institutional reform that implies non-tariff trade cost reductions is the introduction of the European Monetary Union (EMU).

The process of international economic integration has raised many concerns among environmentalists, who argue that the consequent increase in trade flows will lead to increased pollution, and that increased openness of economies will undermine the effectiveness of national environmental 
policies. In particular, there seems to be a widespread belief - not only among environmentalists - that international economic integration increases the need for transnational coordination of environmental policies. For instance, in a fairly recent WTO report on the environmental consequences of increased trade, it is argued that

"...the ongoing dismantling of economic borders reinforces the need to cooperate on environmental matters, especially on transboundary and global environmental problems that are beyond the control of any individual nation." (WTO 1999, p. 1.)

The aim of the present paper is to study the relationship between product market integration and the effect of environmental policy coordination from both an environmental and a welfare perspective - when product markets are characterised by imperfect competition and national policy makers act strategically.

In a world of imperfect competition, national policy makers typically have incentives to use environmental policies strategically to pursue nonenvironmental goals, for example to use emission taxes, or other environmental policy instruments, as strategic trade policy tools. These incentives are particularly relevant when free trade agreements have eliminated the viability of traditional trade policy instruments such as import tariffs or export subsidies. Thus, in a non-cooperative policy game, the chosen environmental policies will typically be determined by the interaction of conflicting policy incentives, so the environmental effect of policy coordination is a priori not clear. In the present paper we analyse how different policy incentives interact in determining the optimal non-cooperative environmental policies, with a particular focus on how product market integration is likely to affect both the environmental and welfare gain of transnational policy coordination. Does international product market integration increase or reduce the distortion of environmental policies in the non-cooperative policy game?

The idea that imperfect competition in global markets creates distorted incentives with respect to national environmental policy making is not new. Early contributions to the literature on 'strategic environmental policy' based on the idea of strategic trade policy in Brander and Spencer (1985) include Conrad (1993), Barrett (1994), Kennedy (1994), Rauscher (1994) and Ulph (1996). The main insight from this body of literature is that national governments, when being prevented from using export subsidies or other direct trade policy instruments, may have incentives to adopt lax environmental standards in order to promote the competitiveness of domestic firms, a policy that has been termed 'ecological dumping,. ${ }^{1,2}$ By applying a model of reciprocal trade - rather than the third-market model of Brander and 
Spencer (1985) - the present paper adds to this literature by studying how the non-cooperative policy incentives, and the efficient (second-best) policy, depend on the degree of product market integration.

The two papers which relate perhaps most closely to the present study are Kennedy (1994) and Burguet and Sempere (2003). In the former paper, a two-country model with oligopolistic competition is used to analyse how strategic interaction between governments can lead to inefficient distortion of pollution taxes in the non-cooperative policy equilibrium. However, there are no costs of trade in that model, so the issue of product market integration (or trade liberalisation) is not tackled. ${ }^{3}$ Burguet and Sempere $(\mathrm{B} \& \mathrm{~S})$, on the other hand, use a related type of framework to analyse how trade liberalisation affects non-cooperative environmental policies and welfare. However, they only focus on the non-cooperative policy game, so the question of how trade liberalisation affects the benefits of policy coordination is not an issue in their paper. We show that trade liberalisation - or product market integration - affects not only the non-cooperative policy outcome, but also the efficient solution. Thus, even if increased integration leads to a more lax environmental policy in the non-cooperative policy game, it does not necessarily follow that the need for policy coordination increases.

There are also other differences between the two above mentioned papers and the present one. In contrast to $\mathrm{B} \& \mathrm{~S}$, who focus on local pollution exclusively, we also allow for transboundary pollution, which has important implications for policy incentives. Furthermore, whereas B\&S analyse trade liberalisation as a bilateral reduction of tariffs, we focus on the effect of non-tariff trade barriers. Finally, in contrast to both Kennedy and $\mathrm{B} \& \mathrm{~S}$, we allow for products to be differentiated, which turns out to play an important role in determining the strength of the different policy incentives.

The basis for our analysis is an international duopoly model of reciprocal trade, in the tradition of Brander and Krugman (1983), where a by-product of the production process is the emission of a pollutant. The analysis rests on the fundamental assumption that free trade agreements prohibit the use of traditional trade policy instruments, so that the available number of policy tools is lower than the number of policy goals, implying that policy makers are operating in a second-best world, at the best. Thus, the analysis is carried out under the assumption that trade costs do not comprise tariffs at all, so that the process of international product market integration is driven by reductions of non-tariff trade costs. Furthermore, in order to make the model tractable and reasonably simple - while still preserving the relevant trade-offs between different policy incentives - we assume that the only available policy instrument is an emission tax. 
In this non-competitive scenario, optimal policy making must balance different and partially conflicting considerations: first, imperfect competition creates an under-provision problem, so there is an incentive to reduce emission taxes in order to increase consumer utility. Second, in the noncooperative policy game there is an incentive to reduce taxes in order to capture oligopoly rents from the foreign country. Third, considerations for environmental damage yield incentives to keep emission taxes high. The strength of these partly conflicting policy incentives, as well as the effect of policy coordination, depend - in different ways - on the degree of product market integration. Stronger integration increases competition, implying that considerations for consumer utility reduce the downward pressure on emission taxes when national policies are coordinated. The relationship between integration and the coordination effect on the two other policy incentives are, however, ambiguous. Regarding the incentives for reducing environmental pollution, increased integration actually reduces the upward pressure on emission taxes when policies are coordinated, provided that pollution is predominantly local. In this case, non-cooperative policy making tends to yield excessively high taxes due to incentives for 'pollutionshifting', and these incentives are reinforced when product markets are integrated.

The main message of the paper is that product market integration does not necessarily increase the need for transnational policy coordination, neither from a purely environmental nor from a social welfare point of view. On the contrary, if the marginal social cost of pollution is constant and there is a certain degree of product differentiation, product market integration always reduces the environmental gain of policy coordination, while the welfare gain is reduced if coordination leads to higher emission taxes. On the other hand, with a quadratic social damage cost function, integration reduces both the environmental and welfare gains of policy coordination if products are sufficiently differentiated and pollution is predominantly local. Given that policy coordination reduces pollution, this means that the process of product market integration in these cases reduces the policy distortions in the non-cooperative policy game and moves the non-cooperative equilibrium closer to the efficient (second-best) solution, in terms of equilibrium emission tax levels. There are two main effects that contribute to these results. In addition to the above mentioned 'pollutionshifting' effect, which applies when pollution is sufficiently local in nature, product market integration also reduces the incentive to keep emission taxes high in the coordination regime in order to curtail the total outlay on trade costs.

The rest of the paper is organised as follows. In the next section we present the fundamental ingredients of the model. In Section 3, the 
non-cooperative equilibrium is derived, and we also consider the effect of product market integration on non-cooperative equilibrium policies. In Section 4 we analyse the environmental effect of a transnational coordination of national policies, and examine under which circumstances policy coordination is likely to reduce total pollution. Section 5 contains the main contribution of the paper. Here we analyse how product market integration influences the effect of policy coordination on environmental policies, and subsequently evaluate how integration affects the environmental and welfare gains of transnational policy coordination. Finally, some concluding remarks, including an elaborate discussion of alternative modelling assumptions, are offered in Section 6.

\section{Model}

Consider a symmetric international duopoly - with firm $i$ located in country $i$, $i=1,2$ - where each firm produces its own variant of a differentiated product. The preferences of a representative consumer in country $i$ is given by a quasilinear utility function

$$
U^{i}=q_{i}^{i}+q_{j}^{i}-\frac{1}{2}\left[\left(q_{i}^{i}\right)^{2}+\left(q_{j}^{i}\right)^{2}+2 b q_{i}^{i} q_{j}^{i}\right]+y
$$

where $q_{j}^{i}$ is the quantity supplied in country $i$ by firm $j$, and $y$ is a numeraire good. With a fixed income, utility maximisation then yields the following inverse demand functions:

$$
\begin{aligned}
& p_{i}^{i}=1-q_{i}^{i}-b q_{j}^{i}, \\
& p_{j}^{i}=1-q_{j}^{i}-b q_{i}^{i},
\end{aligned}
$$

$i, j=1,2, i \neq j$, where $p_{j}^{i}$ is the price of good $j$ (produced by firm $j$ ) in country $i{ }^{4}$ The parameter $b \in[0,1]$ is a measure of the degree of product differentiation, where $b=1$ implies that the goods are homogeneous.

The firms act as Cournot players, and we also adopt the market segmentation hypothesis, implying that each firm chooses its optimal supply of the good for each market separately. There are no fixed costs, and marginal production costs are assumed to be constant and equal for both firms. Without loss of generality, these costs are set equal to zero. There are also some trade costs associated with exports: we assume that each firm has to pay a per-unit cost $t$ for goods supplied to the foreign market. This cost parameter encompasses all non-tariff costs associated with serving a foreign market, such as transportation costs, red tape and 
various regulatory requirements that complicate and/or delay the trading process.

Production of the goods causes emissions of a pollutant. However, the firms have technology available for abating this pollutant, Following Ulph (1996), and others, we choose units such that for output levels $q_{i}^{j}$ and abatement level $a_{i}$, emissions from firm $i$ are given by

$$
E_{i}=\sum_{j} q_{i}^{j}-a_{i}, \quad i, j=1,2
$$

Abatement costs for firm $i$ is given by a convex cost function $C_{i}\left(a_{i}\right)$. For simplicity, we let this function take on a simple quadratic form: $C_{i}=\frac{c}{2} a_{i}^{2}$. An interior solution with respect to equilibrium abatement levels (i.e., $a_{i}<\sum_{j} q_{i}^{j}$ ) require that $c$ is sufficiently large. We follow the specification in Kennedy (1994) and assume that total pollution in country $i, \Omega^{i}$, is given by

$$
\Omega^{i}=E_{i}+\alpha E_{j}, \quad i, j=1,2, \quad i \neq j,
$$

where the parameter $\alpha \in[0,1]$ indicates the degree to which pollution is transboundary. If $\alpha=0$, pollution is purely local, whereas $\alpha=1$ implies that pollution is completely transboundary. ${ }^{5}$

Pollution causes environmental damage, and the social evaluation of these costs is given by a damage cost function $D^{i}:=D\left(\Omega^{i}\right)$, where $D^{\prime}(\cdot)>0$ and $D^{\prime \prime}(\cdot) \geq 0$. Each national policy maker can influence the total level of emissions by levying an emission tax $\tau$ on the domestic firm. We define social welfare in country $i$ as the sum of consumers' and producers' surplus, net of social pollution costs:

$$
W^{i}=U^{i}-\left(p_{i}^{i} q_{i}^{i}+p_{j}^{i} q_{j}^{i}\right)+\pi_{i}+\tau_{i} E_{i}-D^{i} \quad i=1,2,
$$

where $\tau_{i} E_{i}$ is emission tax revenue for the government in country $i$, and $\pi_{i}$ denotes the profits of firm $i$, given by

$$
\pi_{i}=p_{i}^{i} q_{i}^{i}+\left(p_{i}^{j}-t\right) q_{i}^{j}-\tau_{i} E_{i}-C_{i} \quad i, j=1,2, \quad i \neq j .
$$

The game is played in two stages:

- Stage 1: the governments in the two countries decide - cooperatively or non-cooperatively - on the environmental policy by setting emission taxes.

- Stage 2: the firms compete in Cournot fashion by choosing - noncooperatively - abatement levels and output quantities for each market. 


\section{Non-cooperative Policy Making}

For given national policies $\left(\tau_{i}, \tau_{j}\right)$, we can find the equilibrium levels of abatement, and output for each market, by simultaneously solving the firms' profit maximisation problems, yielding

$$
\begin{aligned}
& q_{i}^{i}=\frac{2-b+b t+b \tau_{j}-2 \tau_{i}}{4-b^{2}}, \\
& q_{i}^{j}=\frac{2-b+2 t+b \tau_{j}-2 \tau_{i}}{4-b^{2}}, \\
& a_{i}=\frac{1}{c} \tau_{i},
\end{aligned}
$$

$i, j=1,2, i \neq j$. In equilibrium, we see that each firm abates pollution to the point where marginal abatement costs equal the emission tax rate. We will assume throughout that the equilibrium implies two-way trade. From (9) we see that this requires trade costs to be below a certain prohibitive level. ${ }^{6}$

Anticipating the outcome of the production game, the national policy makers simultaneously and non-cooperatively set emission taxes to maximise (domestic) social welfare. For the subsequent analysis, it will be useful to reformulate the social welfare function in the following way:

$$
W^{i}=U^{i}+S^{i}-D^{i}-C^{i}
$$

where

$$
S^{i}:=\left(p_{i}^{j}-t\right) q_{i}^{j}-p_{j}^{i} q_{j}^{i}
$$

is the net trade surplus for country $i .^{7}$ The first-order condition for an optimal tax rate in country $i$ is then given by

$$
\frac{\partial W^{i}\left(\tau_{i}, \tau_{j}\right)}{\partial \tau_{i}}=\frac{\partial U^{i}\left(\tau_{i}, \tau_{j}\right)}{\partial \tau_{i}}+\frac{\partial S^{i}\left(\tau_{i}, \tau_{j}\right)}{\partial \tau_{i}}-\frac{\partial D^{i}\left(\tau_{i}, \tau_{j}\right)}{\partial \tau_{i}}-\frac{\partial C_{i}\left(\tau_{i}\right)}{\partial \tau_{i}}=0 .
$$

When setting an optimal emission tax rate, each government has to balance four different considerations: consumer utility, net trade surplus, environmental damage and abatement costs. In order better to grasp the intuition for the main results of the model, we will proceed by taking a more in-depth look at the decomposed effects of the first-order condition, evaluated at the symmetric equilibrium $\tau_{1}=\tau_{2}=\tau_{n c}$. Although negative taxes are possible, we 
will assume - for clarity of the subsequent discussion - that the policy equilibrium yields strictly positive emission taxes, which essentially requires that the social cost of pollution is sufficiently high.

Consumer utility. By inserting the equilibrium expressions from stage two of the game, we derive ${ }^{8}$

$$
\frac{\partial U^{i}\left(\tau_{n c}\right)}{\partial \tau_{i}}=-\frac{(2-b)^{2}\left(1+\tau_{n c}(1+b)\right)+b^{3} t}{(2-b)^{2}(2+b)^{2}}<0 .
$$

Thus, considerations for consumer utility pull in the direction of lower emission taxes. This is of course due to the fact that imperfect competition creates an under-provision problem when environmental damages are not taken into account. ${ }^{9}$

Net trade surplus. At the non-cooperative equilibrium we have that

$$
\frac{\partial S^{i}\left(\tau_{n c}\right)}{\partial \tau_{i}}=-\frac{(2-b)\left(2 \tau_{n c}+b\right)-t b^{2}}{(2-b)^{2}(2+b)}<0 .
$$

By increasing taxes for the domestic firm, rents are shifted to the foreign country. Thus, considerations for the net trade surplus - the strategic trade policy incentives - also pull in the direction of a more lax environmental policy.

Environmental damage. Once more, by inserting the equilibrium expression from the production subgame, we derive

$$
-\frac{\partial D^{i}\left(\tau_{n c}\right)}{\partial \tau_{i}}=D^{\prime}(\cdot)\left(\frac{2(2-\alpha b)}{4-b^{2}}+\frac{1}{c}\right)>0,
$$

which illustrates the environmental gains from emission taxation. Increased taxation reduces production and thus pollution. We see that the environmental gain of emission taxes increases if abatement becomes less costly. Note also that a lower value of $\alpha$ yields incentives for a tougher environmental policy (i.e., higher emission taxes). If pollution is predominantly local, uncoordinated taxation implies that each government has an incentive to use the tax instrument to shift (polluting) production to the other country. ${ }^{10}$

Abatement costs. The effect of emission taxes on abatement costs is straightforward. In equilibrium, we have that

$$
-\frac{\partial C^{i}\left(\tau_{n c}\right)}{\tau_{i}}=-\frac{\tau_{n c}}{c}<0,
$$

implying that a higher emission tax rate will increase abatement and thus total abatement costs. 


\subsection{NON-COOPERATIVE EQUILIBRIUM TAX RATES}

Using (14)-(16), the equilibrium non-cooperative emission tax rate is characterised by the following equation:

$$
\begin{aligned}
& -\frac{\left[4+b^{2}(1-b-2 t)+\tau_{n c}(2-b)\left(6+3 b-b^{2}\right)\right]}{\left(4-b^{2}\right)^{2}} \\
& +D^{\prime}(\cdot) \frac{2(2-\alpha b)}{\left(4-b^{2}\right)}+\frac{1}{c}\left[D^{\prime}(\cdot)-\tau_{n c}\right]=0 .
\end{aligned}
$$

We can solve explicitly for the equilibrium tax rate by considering two special cases; linear and quadratic damage costs. For the linear case, assume that $D^{i}=d \Omega^{i}$. Solving (18) yields an equilibrium tax rate, $\bar{\tau}_{n c}$, given by

$$
\bar{\tau}_{n c}=\frac{d(2+b)\left(4+2 c(2-b \alpha)-b^{2}\right)-c\left(2+b+b^{2}-\frac{2 t b^{2}}{(2-b)}\right)}{(2-b)(2+b)^{2}+c\left(6+3 b-b^{2}\right)} .
$$

For the quadratic case, assume that $D^{i}=\frac{d}{2}\left(\Omega^{i}\right)^{2}$. In this case, the equilibrium tax rate, $\tilde{\tau}_{n c}$, is given by

$$
\tilde{\tau}_{n c}=\frac{c\left(d(2-t)(1+\alpha)\left(4+2 c(2-b \alpha)-b^{2}\right)-c\left(2+b+b^{2}-\frac{2 t b^{2}}{(2-b)}\right)\right)}{d(2+b+2 c)(1+\alpha)\left(4+2 c(2-b \alpha)-b^{2}\right)+c(2+b)(4+3 c)-c b^{2}(2+b+c)} .
$$

\subsection{PRODUCT MARKET INTEGRATION}

Before analysing the effects of policy coordination, let us see how product market integration - interpreted as (marginal) reduction of trade costs affects the uncoordinated policy equilibrium. The direction of change can be evaluated by differentiating the first order condition with respect to $t$ while holding the equilibrium tax level $\tau_{n c}$, constant. Once more, it is useful to start out by discussing the decomposed effects. From (14) we easily see that

$$
\frac{\partial^{2} U^{i}\left(\tau_{n c}\right)}{\partial t \partial \tau_{i}}<0
$$

which implies that integration reduces the negative effect of increased taxation on consumer utility. This is due to the fact that product market integration increases the degree of competition, and thus total output, which alleviates the under-provision problem. Ceteris paribus, a reduction of trade costs leads then to a tougher environmental policy. 
From (15) it is also easily seen that

$$
\frac{\partial^{2} S^{i}\left(\tau_{n c}\right)}{\partial t \partial \tau_{i}}>0,
$$

which implies that integration increases incentives for rent-shifting activity by the governments. The reason is simply that lower trade costs make it easier to capture rents from the foreign market. Ceteris paribus, this means that trade cost reductions encourage a more lax environmental policy.

From (16) we can derive

$$
-\frac{\partial^{2} D^{i}\left(\tau_{n c}\right)}{\partial t \partial \tau_{i}}=-D^{\prime \prime}(\cdot) \frac{(1+\alpha)}{(2+b)}\left(\frac{2(2-\alpha b)}{\left(4-b^{2}\right)}+\frac{1}{c}\right) \leq 0 .
$$

Lower trade costs increase total production and thus pollution. This is the socalled 'scale effect' of product market integration. If the damage cost function is strictly convex, this means that the social benefit of reducing pollution increases as a result of reduced trade costs. Thus, environmental considerations call for a tougher environmental policy when product markets become more integrated, as long as the marginal social cost of pollution is increasing.

Finally, we see from (17) that the effect of environmental taxation on total abatement costs are independent of trade costs. The overall effect of trade cost reductions on the equilibrium emission tax rate is found by total differentiation of (18), yielding

$$
\frac{\partial \tau_{n c}}{\partial t}=\frac{c\left(2\left(\frac{b^{2}}{2-b}\right) c-\psi\right)}{c^{2}\left(6+3 b-b^{2}\right)+c(2-b)(2+b)^{2}+(2(1+c)+b) \psi},
$$

where

$$
\psi:=D^{\prime \prime}(\cdot)(1+\alpha)\left[2 c(2-b \alpha)+\left(4-b^{2}\right)\right] \geq 0 .
$$

The following result follows straightforwardly from (24):

Proposition 1. In the non-cooperative equilibrium, product market integration always leads to a more lax environmental policy if the marginal social cost of pollution is constant. With a strictly convex damage cost function, product market integration always leads to a tougher environmental policy if $b$ is sufficiently close to zero.

If the damage cost function is linear, trade cost reduction does not influence how environmental considerations affect the optimal policy; only incentives for rent-shifting and increasing consumer utility are affected. It turns out that 
the rent-shifting effect dominates, implying that integration leads to lower emission taxes, because incentives for rent-shifting are sufficiently strengthened. The strength of both effects are, however, determined by the degree of product differentiation. For instance, the higher the degree of product differentiation the more difficult it is to capture rents from the foreign country by lowering emission taxes. Thus, with increasing marginal costs of pollution, environmental considerations will always dominate if products are sufficiently differentiated, implying that product market integration leads to higher taxes.

\section{Transnational Policy Coordination}

In the coordinated policy regime, the two governments (or a transnational governmental body) optimally set emission taxes to maximise joint welfare. Thus, the maximisation problem is given by:

$$
\begin{aligned}
\max _{\tau_{i}, \tau_{j}}\left(W^{i}+W^{j}\right)= & \left(U^{i}+U^{j}\right)+\left(S^{i}+S^{j}\right) \\
& -\left(D^{i}+D^{j}\right)-\left(C_{i}+C_{j}\right) \quad i \neq j .
\end{aligned}
$$

Performing our usual decomposition of policy incentives, and evaluating at the symmetric cooperative equilibrium $\tau_{1}=\tau_{2}=\tau_{c}$, we can now derive

$$
\begin{aligned}
& \frac{\partial\left[U^{i}\left(\tau_{c}\right)+U^{j}\left(\tau_{c}\right)\right]}{\partial \tau_{i}}=-\frac{2+(1+b)\left(2 \tau_{c}+t\right)}{(2+b)^{2}}<0, \\
& \frac{\partial\left[S^{i}\left(\tau_{c}\right)+S^{j}\left(\tau_{c}\right)\right]}{\partial \tau_{i}}=\frac{t}{2+b}>0, \\
& -\frac{\partial\left[D^{i}\left(\tau_{c}\right)+D^{j}\left(\tau_{c}\right)\right]}{\partial \tau_{i}}=D^{\prime}(\cdot)(1+\alpha)\left(\frac{2}{2+b}+\frac{1}{c}\right)>0 . \\
& -\frac{\partial\left[C_{i}\left(\tau_{c}\right)+C_{j}\left(\tau_{c}\right)\right]}{\partial \tau_{i}}=-\frac{\tau_{i}}{c}<0 .
\end{aligned}
$$

Comparing with the non-cooperative solution, there are two important aspects to note. First, incentives for rent-shifting are now eliminated. Instead, the countries have a common incentive to increase taxes in order to reduce costly trade, as illustrated by (27). Second, the marginal environmental 
benefit of emission taxation is now increasing in $\alpha$, since 'pollution-shifting' incentives are eliminated by policy coordination.

\subsection{EQUILIBRIUM TAX RATES UNDER POLICY COORDINATION}

Using (26)-(28), the optimal emission tax rate in the coordinated equilibrium is given by the solution to

$$
-\frac{\left(2+2 \tau_{c}(1+b)-t\right)}{(2+b)^{2}}+D^{\prime}(\cdot) \frac{2(1+\alpha)}{2+b}+\frac{1}{c}\left[(1+\alpha) D^{\prime}(\cdot)-\tau_{c}\right]=0 .
$$

Once more, we can solve explicitly for the equilibrium tax rate in the coordination regime by considering the special cases of linear and quadratic damage costs. These are given, respectively, by

$$
\begin{aligned}
& \bar{\tau}_{c}=\frac{d(2+b)(2+b+2 c)(1+\alpha)-c(2-t)}{(2+b)^{2}+2 c(1+b)}, \\
& \tilde{\tau}_{c}=\frac{(2-t) c\left(d(1+\alpha)^{2}(2+b+2 c)-c\right)}{d(2+b+2 c)^{2}(1+\alpha)^{2}+c\left((2+b)^{2}+2 c(1+b)\right)} .
\end{aligned}
$$

\subsection{DOES POLICY COORDINATION REDUCE POLLUTION?}

With multiple distortions, transnational policy coordination does not necessarily lead to higher emission taxes and reduced pollution. We can examine the effect of policy coordination by evaluating the changes in policy incentives at the non-cooperative equilibrium. Policy coordination leads to a tougher environmental policy (i.e., higher emission taxes) if

$$
\frac{\partial W^{j}\left(\tau_{n c}\right)}{\partial \tau_{i}}=\frac{\partial U^{j}\left(\tau_{n c}\right)}{\partial \tau_{i}}+\frac{\partial S^{j}\left(\tau_{n c}\right)}{\partial \tau_{i}}-\frac{\partial D^{j}\left(\tau_{n c}\right)}{\partial \tau_{i}}-\frac{\partial C_{j}\left(\tau_{n c}\right)}{\partial \tau_{i}}>0 .
$$

Comparing (17) and (29), we see that there are no policy distortions with respect to abatement costs. However, the remaining policy incentives are affected by coordination. Regarding considerations for consumer utility, we find that

$$
\frac{\partial U^{j}\left(\tau_{n c}\right)}{\partial \tau_{i}}=-\frac{(2-b)^{2}\left[1+\tau_{n c}(1+b)\right]+\left(4-3 b^{2}\right) t}{\left(4-b^{2}\right)^{2}}<0,
$$


which implies that coordination yields incentives for lower taxes. In the noncoordination regime, each policy maker does not care about the share of domestic production that is consumed by foreigners, so the full extent of the under-provision problem is not taken into account. When national policies are coordinated, though, this effect is internalised.

The effect of policy coordination on rent-shifting incentives is given by

$$
\frac{\partial S^{j}\left(\tau_{n c}\right)}{\partial \tau_{i}}=\frac{(2-b)\left(2 \tau_{n c}+b\right)+4(1-b) t}{(2-b)^{2}(2+b)}>0 .
$$

From a comparison of (15) and (27), this effect is obvious. By eliminating rent-shifting incentives, policy coordination yields - all else equal - incentives for a tougher environmental policy.

Finally, the change in policy incentives that is related to environmental considerations is given by.

$$
-\frac{\partial D^{j}\left(\tau_{n c}\right)}{\partial \tau_{i}}=-D^{\prime}(\cdot) \frac{\partial \Omega^{j}\left(\tau_{n c}\right)}{\partial \tau_{i}}=D^{\prime}(\cdot)\left[\frac{2(2 \alpha-b)}{\left(4-b^{2}\right)}+\frac{\alpha}{c}\right] .
$$

We see that

$$
-\frac{\partial D^{j}\left(\tau_{n c}\right)}{\partial \tau_{i}}>(<) 0 \text { iff } \alpha>(<) \hat{\alpha},
$$

where

$$
\hat{\alpha}:=\frac{2 b c}{4 c+\left(4-b^{2}\right)} \in\left(0, \frac{1}{2}\right) .
$$

From the definition of $\hat{\alpha}$, it follows that policy coordination always increases the marginal environmental benefit of emission taxes - implying, all else equal, that taxes are increased - if $\alpha>\frac{1}{2}$ or if products are unrelated $(b=0)$, whereas the opposite is true if pollution is purely local $(\alpha=0)$. When pollution is highly transboundary, non-coordinated policies imply too low taxes - from an environmental perspective - because the negative externality on the other country's environment is not taken into account. However, when pollution is predominantly local, non-coordinated policies imply excessively high taxes - still from an environmental perspective because each local policy maker is trying to shift polluting production to the other country. This last effect is more pronounced the less differentiated the products are. We also observe that $\frac{\partial \hat{\alpha}}{\partial c}>0$, implying that a better abatement technology (lower $c$ ) will increase the parameter space in which policy coordination increases the marginal environmental benefit of emission taxation. 
Comparing the strength of the different policy incentives, we derive the following result regarding the environmental effect of policy coordination: ${ }^{11}$

Proposition 2. Sufficient conditions for transnational policy coordination to reduce environmental pollution are $b>\frac{1}{2} \sqrt{17}-\frac{3}{2} \approx 0.56$ and $\alpha>\hat{\alpha}$.

Thus, unless products are too differentiated or pollution is predominantly local, policy coordination will always lead to increased emission taxes. This result is explained by two different effects. First, we know that rent-shifting incentives in the non-cooperative regime are stronger the less differentiated the products are. Thus, if products are sufficiently close substitutes, the elimination of rent-shifting incentives dominates the increased incentives for alleviating the under-provision problem when national policies are coordinated. If, in addition, pollution is transboundary to a sufficient degree, environmental considerations also imply that policy coordination leads to higher taxes. On the other hand, if products are sufficiently differentiated, or if pollution is predominantly local, the environmental effect of policy coordination is generally ambiguous. ${ }^{12}$

Note that the conditions given in Proposition 2 are sufficient, but not necessary. For the special case of linear damage costs, we are able to derive an explicit necessary condition. In this case, policy coordination will increase emission taxes, and thus reduce total environmental pollution, if

$$
\alpha>\bar{\alpha}:=\frac{\frac{(1-d)}{d}\left[2-3 b-b^{2}+2 c(1-b)\right]-\frac{t}{(2-b) d}\left[(1-b)(4+3 c)-b^{2}\right]}{\frac{1}{c}(2-b)(2+b)^{2}+7(2+b)+2 c(3+b)-b^{2}} .
$$

\section{Product Market Integration and Policy Coordination}

The degree of product market integration - interpreted as the level of trade costs - is influential in determining the effect of policy coordination. In this Section we analyse how product market integration affects the outcome of policy coordination, with respect to changes in emission taxes, and ask whether such integration increases the benefit of coordination, both in terms of total emission reductions and social welfare gains.

We start out by analysing how the effect of policy coordination - in terms of changes in equilibrium emission taxes - is determined by the degree of product market integration. As follows from the analysis in the previous Section, this is given by the second-order cross derivative $\frac{\partial^{2} W^{j}\left(\tau_{n c}\right)}{\partial t \partial \tau_{i}}$. Again, we proceed by considering the decomposed effects. Product market 
integration does not affect incentives for reducing abatement costs (cf. (17) and (29)), but the other policy incentives are all influenced by trade cost reductions.

From (33) we have that

$$
\frac{\partial^{2} U^{j}\left(\tau_{n c}\right)}{\partial t \partial \tau_{i}}=-\frac{\gamma+(1+b)(2-b)^{2} \frac{\partial \tau_{n c}}{\partial t}}{\left(4-b^{2}\right)^{2}}
$$

where

$$
\gamma:=4-3 b^{2}>0
$$

By inserting the expression for $\frac{\partial \tau_{n c}}{\partial t}$ from (24) we derive

$$
\begin{aligned}
& \frac{\partial^{2} U^{j}\left(\tau_{n c}\right)}{\partial t \partial \tau_{i}}= \\
& -\frac{\psi\left[\frac{\gamma}{2+b}+c(1-b)\right]+\frac{c^{2}}{2+b}\left(12-9 b^{2}+b^{3}\right)+c \gamma(2-b)}{(2-b)^{2}\left[c^{2}\left(6+3 b-b^{2}\right)+c(2-b)(2+b)^{2}+\psi(2(1+c)+b)\right]}<0 .
\end{aligned}
$$

Since $\frac{\partial \nu^{j}\left(\tau_{n c}\right)}{\partial \tau_{i}}<0$, it follows from (39) that product market integration reduces the coordination effect with respect to consumer utility. This result is explained simply by the fact that lower trade costs leads to increased competition. The subsequent decrease in consumer prices reduces the inefficiency caused by imperfect competition in the first place. Ceteris paribus, this means that integration enlarges the parameter space in which policy coordination results in higher emission taxes.

The relationship between trade costs and the coordination effect on rentshifting incentives is derived from (34), yielding

$$
\frac{\partial^{2} S^{j}\left(\tau_{n c}\right)}{\partial t \partial \tau_{i}}=2 \frac{2(1-b)+(2-b) \frac{\partial \tau_{n c}}{\partial t}}{(2-b)^{2}(2+b)}
$$

from which, when inserting for $\frac{\partial \tau_{n c}}{\partial t}$, we derive

$$
\begin{aligned}
& \frac{\partial^{2} S^{j}\left(\tau_{n c}\right)}{\partial t \partial \tau_{i}}= \\
& \frac{2\left[2 \mu\left[\psi+c\left(4-b^{2}\right)\right]+2 c^{2}\left(3 \mu+b^{3}\right)+\psi c(2-3 b)\right]}{(2-b)^{2}(2+b)\left[c(2-b)(2+b)^{2}+c^{2}\left(6+3 b-b^{2}\right)+\psi(2+b+2 c)\right]},
\end{aligned}
$$


where

$$
\mu:=(2+b)(1-b)>0
$$

A closer inspection of (41) shows that sufficient conditions for product market integration to reduce the coordination effect on rent-shifting incentives, i.e., $\frac{\partial^{2} S^{j}\left(\tau_{n c}\right)}{\partial t \partial \tau_{i}}>0$, are $b<\frac{2}{3}$ or $D^{\prime \prime}(\cdot)=0$. The intuition is somewhat intricate, but still tractable. For a given level of emission taxes, integration implies that incentives for rent-shifting activity in the non-cooperative regime are increased - cf. (22). However, lower trade costs also reduce incentives for using environmental policy to reduce the amount of two-way trade in the coordination regime - cf. (27). For $b<1$, it turns out that the second effect dominates, implying that product market integration reduces the coordination effect on rent-shifting incentives, and more so the higher the degree of product differentiation, because rent-shifting incentives are then less sensitive to the level of trade costs in the non-cooperative regime. These are the direct effects. However, we are evaluating the coordination effects at the non-coordinated equilibrium, so a reduction of trade costs also implies that $\tau_{n c}$ changes. If $\frac{\partial \tau_{n c}}{\partial t}$ is positive, product market integration means that $\tau_{n c}$ goes down, which reduces the incentives for rent-shifting in the non-coordinated regime. This reinforces the result that product market integration reduces the coordination effect on rent-shifting incentives. Indeed, from Proposition 1 we know that $\frac{\partial \tau_{n c}}{\partial t}>0$ if $D^{\prime \prime}(\cdot)=0$, which explains why the characteristics of the damage cost function matters for the sign of $\frac{\partial^{2} S^{\prime}\left(\tau_{n c}\right)}{\partial t \partial \tau_{i}}$.

If $\frac{\partial^{2} S^{j}\left(\tau_{n c}\right)}{\partial t \partial \tau_{i}}>0$, consumer utility and rent-shifting incentives work in opposite directions with respect to the effects of policy coordination when product markets become more integrated. Concerns for consumer utility put a downward pressure on environmental taxes when national policies are coordinated, but this pressure is reduced when trade costs are lowered. Conversely, the elimination of rent-shifting incentives through policy coordination puts an upward pressure on emission taxes, but this effect is also reduced by product market integration. In this case, the sum of these two effects are generally ambiguous.

Finally, then, let us see how the degree of product market integration determines the coordination effect on incentives to reduce pollution. From (35) we have that

$$
-\frac{\partial^{2} D^{j}\left(\tau_{n c}\right)}{\partial t \partial \tau_{i}}=D^{\prime \prime}(\cdot)\left(\frac{\partial \Omega^{j}\left(\tau_{n c}\right)}{\partial \tau_{i}} \frac{\partial \tau_{n c}}{\partial \tau}+\frac{\partial \Omega^{j}\left(\tau_{n c}\right)}{\partial t}\right)\left(\frac{2(2 \alpha-b)}{\left(4-b^{2}\right)}+\frac{\alpha}{c}\right) .
$$

By inserting for $\frac{\partial \boldsymbol{\Omega}^{j}\left(\tau_{n c}\right)}{\partial \tau_{i}}, \frac{\partial \boldsymbol{\Omega}^{j}\left(\tau_{n c}\right)}{\partial t}$ and $\frac{\partial \tau_{n c}}{\partial t}$ we drive 


$$
\begin{aligned}
& -\frac{\partial^{2} D^{j}\left(\tau_{n c}\right)}{\partial t \partial \tau_{i}}= \\
& \frac{(1+\alpha) D^{\prime \prime}(\cdot)\left[c\left(6-3 b+b^{2}\right)+\left(8-4 b+b^{3}\right)\right]\left[2 c(b-2 \alpha)-\alpha\left(4-b^{2}\right)\right]}{(2-b)^{2}(2+b)\left[\psi(2+2 c+b)+c^{2}\left(6+3 b-b^{2}\right)+c(2-b)(2+b)^{2}\right]} .
\end{aligned}
$$

We can first note that $-\frac{\partial^{2} D^{j}\left(\tau_{n c}\right)}{\partial t \partial \tau_{i}}=0$ if the marginal social cost of pollution is constant. Since the marginal effect of taxation on emissions is independent of trade costs, product market integration does not influence the coordination effect on incentives for emission reductions if marginal damage costs are independent of the level of pollution. For strictly convex damage costs, however, we see that $-\frac{\partial^{2} D^{\prime}\left(\tau_{n c}\right)}{\partial t \partial \tau_{i}}>0$ if $\alpha<\hat{\alpha}$. In this case - when pollution is predominantly local - environmental considerations put a downward pressure on emission taxes when national policies are coordinated, due to the elimination of 'pollution-shifting' incentives. ${ }^{13} \mathrm{~A}$ reduction of trade costs implies that total production increases, with an equivalent increase in total emissions. Due to the convexity of the damage cost function, higher emissions increase the incentives to shift polluting production to the other country by setting high taxes in the non-coordinated regime. Consequently, lower trade costs imply that the coordination effect increases. All else equal, product market integration then increases the parameter space - due to purely environmental considerations - in which coordination leads to lower emission taxes! The 'inverse intuition' applies when $\alpha>\hat{a}$.

\subsection{ENVIRONMENTAL POLLUTION}

From an environmentalist perspective, a key question is whether or not product market integration increases the environmental gain of policy coordination. In other words: how does product market integration influence the effectiveness of transnational policy coordination as a means to reduce pollution?

We interpret the 'environmental gain' of policy coordination simply as the reduction of total environmental pollution in country $i$, i.e., $\Omega^{i}\left(\tau_{c}\right)-\Omega^{i}\left(\tau_{n c}\right)$. Since equilibrium pollution is linear in taxes, and the marginal effect of taxation on total emissions is independent of trade costs, product market integration will increase the environmental gain (or reduce the loss) of policy coordination if $\frac{\partial\left(\tau_{c}-\tau_{n c}\right)}{\partial t}<0 .{ }^{14}$

Since $\frac{\partial\left(\tau_{c}-\tau_{n c}\right)}{\partial t}<0$ if $\frac{\partial^{2} W^{j}\left(\tau_{n c}\right)}{\partial t \partial \tau_{i}}<0$, the answer to the posed question is found by considering the sum of the previously analysed decomposed effects. However, in order to derive somewhat more clear-cut answers, we consider the special cases of linear and quadratic damage cost functions. The relationship between the degree of product market integration and the 
environmental effect of transnational policy coordination can then be summarised as follows.

Proposition 3. (i) With linear damage costs, product market integration reduces the environmental gain of policy coordination unless $b \geq \bar{b}$, where $\bar{b}$ is an increasing function of the abatement cost parameter $c$, and given by

$$
\bar{b}:=\frac{1}{2}(\sqrt{(3 c+8)(3 c+4)}-4-3 c) \in(0.83,1) .
$$

(ii) With a quadratic damage cost function, product market integration reduces the environmental gain of policy coordination if both $\alpha$ and $b$ are sufficiently small.

From an environmental perspective, it appears that the process of increased product market integration between countries does not necessarily imply an increased need for transnational policy coordination. Unless products are very close substitutes, this is actually never the case when the social marginal cost of pollution is constant, so that the 'scale effect' of increased integration does not affect the marginal incentives for reducing pollution. ${ }^{15}$ But even with a strictly convex damage cost function, increased integration reduces the environmental gain from policy coordination if products are sufficiently differentiated and pollution is predominantly local.

As the previous analysis indicates, two different effects contribute to this result. First, lower trade costs reduce the incentives to keep taxes high in the coordination regime in order to reduce total outlay on trade costs. Second, and perhaps most noteworthy, product market integration increases the incentives for 'pollution-shifting' in the non-coordinated regime if $\alpha$ is sufficiently low, and these incentives are eliminated through policy coordination. Thus, if pollution is predominantly local, product market integration could lower the environmental gain from policy coordination due to purely environmental considerations.

Finally, it should be noted that we have used changes in total emissions as the measure of the environmental gain of policy coordination. An alternative measure is the social valuation of such changes, as represented by the damage cost function $D$. If $D$ is linear in total emissions, there is of course a monotonous correspondence between the two measures. However, if $D$ is strictly convex, the social valuation of a given reduction in total emissions depends on the initial level of pollution, which, in turn, depends on the degree of product market integration. Although a full analytical characterisation is infeasible, numerical simulations suggest that results are qualitatively similar for the two measures. 


\subsection{SOCIAL WELFARE}

Let us now turn to the effect of product market integration and policy coordination on social welfare, which is arguably the more relevant perspective when assessing the need for transnational policy coordination. Even if integration reduces the environmental gain from coordination, it may well be that incentives for policy coordination increase from a viewpoint of social welfare. Due to the distorted incentives in the non-cooperative game, there is always a welfare gain from policy coordination. Furthermore, the symmetry of the model ensures that the cooperative solution is in the core. Our concern, however, is how product market integration affects the welfare gain of policy coordination. In other words, does product market integration bring social welfare in the non-cooperative equilibrium closer to the efficient (secondbest) level?

Due to analytical tractability, we will here focus on the two special cases of linear and quadratic damage cost functions. In the first case, when the marginal social cost of pollution is constant, equilibrium emission taxes in the two policy regimes are given by (19) and (31). From these, the social welfare gain of policy coordination can be derived by straightforward calculation:

$$
W^{i}\left(\bar{\tau}_{c}\right)-W^{i}\left(\bar{\tau}_{n c}\right)=\frac{(2+b)^{2} \Phi^{2}}{2(2-b)^{2} c \beta^{2}\left[(2+b)^{2}+2 c(1+b)\right]},
$$

where

$$
\begin{aligned}
\Phi:= & c(2-b)(1-d)\left[2-3 b-b^{2}+2 c(1-b)\right] \\
& \quad-\alpha d(2-b)\left[(2-b)(2+b)^{2}+c\left(7(2+b)+2 c(3+b)-b^{2}\right)\right] \\
& -t c\left[(4+3 c)(1-b)-b^{2}\right], \\
\beta:= & (2-b)(2+b)^{2}+c\left(6+3 b-b^{2}\right)>0 .
\end{aligned}
$$

From (44) we are able to derive the following result:

Proposition 4. If the marginal social cost of pollution is constant, product market integration reduces the welfare gain of policy coordination if $\bar{\tau}_{c}>\bar{\tau}_{n c}$ and $b<\bar{b}$.

When seen in conjunction with (37), the Proposition implies that product market integration will reduce the need for policy coordination - from a 
social welfare perspective - if pollution is transboundary to a sufficient degree: $\alpha>\bar{\alpha}$. From the definition of $\bar{b}$ (given in Proposition 3), this result always holds if $b<0.83$. Note also that $b<\bar{b}$ is a sufficient, but not necessary, condition. It proves infeasible to provide a necessary condition, but numerical simulations suggest that the result given in Proposition 4 - that integration reduce the welfare gain of coordination if such coordination leads to higher emission taxes - also holds for $b \geq \bar{b}$ in the vast majority of cases.

The intuition behind this result can be explained by considering the coordination effects on total pollution and rent-shifting incentives. The key factor is the condition $\bar{\tau}_{c}>\bar{\tau}_{n c}$. When trade costs are strictly positive, $\bar{\tau}_{c}>\bar{\tau}_{n c}$ implies not only that policy coordination reduces the social costs of pollution, but also that the net trade surplus for each country increases. ${ }^{16}$ This follows from the fact that higher taxes dampen the firms' rent-capturing incentives and reduce the amount of costly trade. However, product market integration reduces these trade costs, implying that the positive effect of policy coordination on the net trade surplus is reduced correspondingly. In addition, we already know - from Proposition 3 - that product market integration reduces the environmental gain of policy coordination if $b<\bar{b}$. These two effects combined always dominate the effect on consumer utility.

For the case of a quadratic damage cost function, it proves infeasible to derive analytical results. Consequently, we present our results in the form of numerical examples, using the equilibrium emission taxes given by (20) and (32). Table I presents the effect of product market integration on the welfare gain of policy coordination for different values of the key parameters $\alpha$ and $b$. The results in Table I are presented for a single value of each of the remaining parameters $d$ and $c$, but several numerical simulations with other parameter values produce qualitatively similar results.

A clear pattern emerges: product market integration reduces the welfare gain of policy coordination if products are sufficiently differentiated and pollution is predominantly local. These cases are highlighted in bold type in

Table I. Welfare gain of policy coordination: $W^{i}(\tilde{\tau})_{c}-W^{i}\left(\tilde{\tau}_{n c}\right)$

\begin{tabular}{|c|c|c|c|c|c|c|}
\hline \multirow[b]{2}{*}{$\mathrm{t}$} & \multicolumn{2}{|l|}{$\mathrm{b}=0.2$} & \multicolumn{2}{|l|}{$\mathrm{b}=0.5$} & \multicolumn{2}{|l|}{$\mathrm{b}=0.8$} \\
\hline & $\alpha=0.2$ & $\alpha=0.8$ & $\alpha=0.2$ & $\alpha=0.8$ & $\alpha=0.2$ & $\alpha=0.8$ \\
\hline 0 & 0.0001 & 0.0343 & 0.0012 & 0.0529 & 0.0037 & 0.0818 \\
\hline 0.1 & 0.0003 & 0.0333 & 0.0014 & 0.0503 & 0.0037 & 0.0758 \\
\hline 0.2 & 0.0005 & 0.0322 & 0.0017 & 0.0478 & 0.0037 & 0.0700 \\
\hline 0.3 & 0.0007 & 0.0312 & 0.0020 & 0.0453 & 0.0036 & 0.0645 \\
\hline 0.4 & 0.0010 & 0.0301 & 0.0023 & 0.0429 & 0.0036 & 0.0591 \\
\hline 0.5 & 0.0014 & 0.0291 & 0.0026 & 0.0406 & 0.0036 & 0.0540 \\
\hline
\end{tabular}

Assumptions: $c=10, d=1$. 
Table I. There are two interesting features of these results. First, it is confirmed that product market integration may indeed reduce the need for policy coordination also in the case of a quadratic damage cost function. Second, compared with the case of linear damage costs, we see that the results are partially reversed with respect to the key parameter $\alpha$. In the linear case, product market integration reduced the welfare gain of policy coordination if $\alpha$ was sufficiently high, while $\alpha$ must be sufficiently low to produce this result with quadratic damage costs.

This illustrates indeed that the characteristics of the social damage cost function plays an important role for the coordination effects of product market integration. Intuitively, the reason why the properties of the damage cost function matter should be connected to the environmental effect of policy coordination. This is confirmed by juxtaposing Table I with the second part of Proposition 3, where we see that sufficiently low values of $\alpha$ and $b$ are precisely the conditions securing that product market integration reduces the environmental gain of policy coordination when social damage costs are quadratic in the level of pollution. From Table 1 it follows that the social welfare gain of policy coordination is correspondingly reduced.

\section{Discussion and Concluding Remarks}

It is often claimed that the process of international product market integration contributes towards undermining national environmental policy making and increasing incentives for 'eco-dumping'. The obvious response is to call for environmental policies to be transnationally coordinated. In this paper we have studied how the degree of product market integration affects the gains of policy coordination, with respect to both environmental pollution reductions and social welfare, in a context of imperfect competition and reciprocal trade.

Within the framework of an international Cournot duopoly, we find that product market integration - interpreted as a reduction of trade costs between countries - does not necessarily increase the gain of transnational policy coordination, neither from an environmental nor from a welfare perspective. If the marginal social cost of pollution is constant, product market integration always reduce the environmental gain of policy coordination (unless products are close to homogeneous), while the welfare gain of coordination is reduced if such coordination leads to higher emission taxes. On the other hand, if the social damage cost function is quadratic, product market integration reduces both the environmental and welfare gain of coordination if products are sufficiently differentiated and pollution is predominantly local. Thus, our results suggest that the process of economic integration of product markets might reduce the need for transnational policy coordination, not only from a purely environmentalist perspective, but 
also from a viewpoint of aggregate social welfare. To the extent that product market integration is the result of political decisions, integration and coordination can then be viewed as (imperfect) 'policy substitutes'.

The analysis rests on the key assumption that there are more policy goals than instruments, so that different (and often conflicting) policy incentives must be balanced by the use of a single policy instrument. This is a fundamental premise in the literature on strategic environmental policy, and is justified by the widespread and increasing unavailability of traditional trade policy instruments due to free trade agreements and other types of transnational regulation, such as the European Common Market. In our model, to make things fairly simple, we have focused on an emission tax as the only available policy instrument. It should be noted, though, that although the availability of more policy instruments would better empower policy makers to reach their objectives, incentives to seek foreign rents and to shift pollution elsewhere will still be present among policy makers who interact strategically in a non-cooperative policy game.

In order to provide tractable results for a rather complicated problem, the analysis has been undertaken within a fairly stylised modelling framework. It is thus natural to ask if and how the results are affected by alternative modelling assumptions. In the following we will discuss likely effects of some extensions or alternative assumptions. It is unfeasible to give clear-cut answers to the impact on the main results of the paper, but it is, in most cases, possible to say something about how the different policy incentives are likely to be affected.

It is well known from strategic trade literature that policy incentives are sensitive to the mode of product market competition. An obvious alternative assumption is to let the firms engage in Bertrand competition and set prices instead of quantities. How is this likely to affect our results? Most importantly, the mode of competition affects optimal non-cooperative policies with respect to rent-shifting incentives. With price competition, the optimal rentshifting policy is an export tax, rather than a subsidy (see, e.g., Eaton and Grossman 1986). In our context, this means that emission taxes should tend to be higher under Bertrand competition. In addition, we also know that Bertrand competition yields lower equilibrium prices, compared with the Cournot assumption (see, e.g., Singh and Vives 1984). This implies that incentives for keeping emission taxes low in order stimulate competition and increase consumer utility are reduced. Furthermore, lower prices - and thus higher output - means that total emissions are higher. If the social damage cost function is strictly convex, this should increase incentives for using emission taxes to reduce environmental pollution. Since all these effects pull in the same direction, we should generally expect higher equilibrium emission 
taxes in industries that are characterised by Bertrand competition, both in the cooperative and non-cooperative regime.

It is also natural to ask what would happen if we depart from the duopoly assumption. In an $n$-firm oligopoly, the number of firms in the industry will generally affect incentives for strategic environmental policy. More firms will increase competition in the industry, which reduces the under-provision problem and increases total emissions. As explained above, this should - all else equal - lead to higher emission taxes in equilibrium. Furthermore, increased competition also introduces a new effect with respect to rentshifting incentives. With more than one firm in each country, each 'domestic' firm imposes a negative externality on other domestic firms in the export market. A domestic policy maker can partly alleviate this effect by raising emission taxes. ${ }^{17}$ Like in the case of Bertrand competition, equilibrium emission taxes are expected to increase.

The present model implicitly assumes that each policy maker can commit to a particular tax policy before firms make their strategic decisions. However, the degree of commitment power might differ between national policy makers. If so, it might be more appropriate to assume that the government in one country is a Stackelberg leader vis-à-vis the government in the other country. This makes the model - and thus the equilibrium outcoume asymmetric, since emission taxes will generally differ between the countries in the non-cooperative equilibrium. For that reason it is hard to produce analytical results. However, numerical simulations suggest that relative changes in equilibrium tax rates, compared with two-stage simultaneous move game, are generally very small. The exception is the case of highly transboundary pollution. In this case, the Stackelberg leader will generally set a markedly lower emission tax rate than the Stackelberg follower. If there are little or no incentives for 'pollution-shifting', the Stackelberg leader will commit to a very low tax rate in order to capture more rents from the foreign country. For a large set of parameters, though, results are expected to be quite similar between the two model variants.

In line with the bulk of the literature on strategic environmental policy, the present analysis has been performed within a partial equilibrium framework. Although this framework is suitable for studying strategic interaction, there might be potentially important general equilibrium effects that are omitted. For example, Rauscher (1994) and Elbers and Withagen (2002a, b) show that general equilibrium models might produce qualitatively different results than partial equilibrium models. In a general equilibrium framework, environmental policies will generally affect the allocation of resources (capital and labour) in the economy through the rate of return and thereby the overall effect of such policies. More specifically, lower emission taxes in a sector is likely to reduce the price of goods produced in this sector and induce an 
outflow of resources to other sectors in the economy. With non-discriminatory emission taxes, Rauscher (1994) argues that lower emission taxes might cause a positive net flow of production factors to non-tradable sectors. This could yield opposite result in the sense that rent-shifting incentives might imply higher, rather than lower, emission taxes. However, it is also possible to identify general equilibrium effects that could reinforce incentives for 'ecodumping'. For example, environmental policies might be used as an instrument to influence the location of firms in an international industry. More specifically, a national policy maker might induce entry of foreign firms by lowering emission taxes. This effect is identified by, e.g., Pflüger (2001) and Neary (2006) in general equilibrium models of economic geography. Thus, it is hard to predict whether and how general equilibrium effects are likely to qualitatively influence the overall results.

Finally, it should be said that the quest for analytical tractability has necessitated the use of some specific functional forms. The generality of our results is thus limited by the use of linearity assumptions with respect to demand and technology. However, from the discussion of the different policy incentives we believe that the qualitative nature of these incentives are fairly general. Furthermore, in the cases where opposing forces produce ambiguous results - which is a general feature of the entire analysis - these ambiguities will obviously persist under more general assumptions.

\section{Acknowledgements}

This paper was partly written during a visit at Wissenschaftszentrum Berlin für Sozialforschung (WZB), whose hospitality is gratefully acknowledged. Comments and suggestions from Kjell Erik Lommerud, Frode Meland and two anonymous referees are also greatly appreciated.

\section{Notes}

1. A related body of literature focus on the interaction between trade policy and environmental policy instrument, see, e.g., Walz and Wellisch (1997) and Tanguay (2001).

2. Incentives for 'ecolocigal dumping' when plant locations are endogenous are analysed by, e.g., Markusen et al. (1993, 1995), Hoel (1997) and Ulph and Valentini (2001). In a related context, Buchholz and Konrad (1994) study the strategic choice of technology adoption. There is also a large body of literature on environmental polices and trade in a competitive framework, see, e.g., Copeland and Taylor (1994, 1995).

3. In a similar type of framework, and still without any trade costs, Duval and Hamilton (2002) study strategic environmental policy when markets are asymmetric.

4. Regarding notation, the following convention is adopted throughout the paper: subscripts attached to a variable indicate the firm/product, whereas superscripts indicate the country.

5. This is not the only plausible way to model transboundary pollution. An alternative specification could be $\Omega^{i}=(1-\alpha) E_{i}+\alpha E_{j}$. This would, however, not change our results qualitatively. 
6. From (9) we see that whether or not the equilibrium is characterised by two-way trade also depends on the level of emission taxes. These are, however, endogenously determined in the model. Under the basic assumption that taxes are never set so high that firms do not find it profitable to operate even in their home markets, the assumption of two-way trade boils down to the assumption that trade costs are sufficiently low. For zero emission taxes, two-way trade prevails if $t<1-\frac{b}{2}$. For a related discussion in a similiar type of model, see also Naylor (1998, 1999), where production costs of firms are determined by monopoly trade unions.

7. Explicit expressions for the different welfare components are given in Appendix

8. In order to save notation, we apply the notational shorthand $\frac{\partial U^{i}\left(\tau_{n c}\right)}{\partial \tau_{i}}$ for $\left.\frac{\partial U^{i}\left(\tau_{i}, \tau_{j}\right)}{\partial \tau_{i}}\right|_{\tau_{i}=\tau_{j}=\tau_{n c}}$.
This practice is adopted throughout the paper.

9. As observed by Barnett (1980), imperfectly competitive and polluting firms may underproduce from a social perspective if the market power effect outweighs the environmental damages.

10. This 'pollution-shifting' effect was identified by Kennedy (1994).

11. The proof of this and all subsequent Propositions are given in Appendix.

12. In a setting of imperfect competition and strategic environmental policy, Greaker (2003) also observes the possibility that policy coordination could lead to lower emission taxes, but for different reasons. In his model, the possibility that higher emission taxes could reduce the marginal cost of production (emissions as an inferior input' to production) implies that taxes will be set excessively high in the noncooperative equilibrium.

13. Remember that $-\frac{\partial D^{j}\left(\tau_{c}\right)}{\partial \tau_{i}}<0$ when $\alpha<\widehat{\alpha}$.

14. Since the sign of $\left(\tau_{c}-\tau_{n c}\right)$ is generally ambiguous, we can also make the following interpretation: $\frac{\partial\left(\tau_{c}-\tau_{n c}\right)}{\partial t}<(>) 0$ implies that product market integration enlarges (reduces) the parameter space in which policy coordination will reduce environmental pollution.

15. Furthermore, since $\frac{\partial \Omega^{i}\left(\tau_{c}\right)}{\partial t}<0$ (due to the 'scale effect' of integration) it follows that product market integration reduces the relative environmental gain from policy coordination even more.

16. It is straightforward to verify that $S^{i}\left(\bar{\tau}_{c}\right)>S^{i}\left(\bar{\tau}_{n c}\right)$ iff $\alpha>\bar{\alpha}$.

17. See, e.g., Dixit (1984) for a further discussion of the effect of market structure on strategic trade policy incentives in an international oligopoly.

\section{References}

Barnett, A. H. (1980), 'The Pigouvian Tax Rule Under Monopoly', American Economic Review 70, 1037-1041.

Barrett, S. (1994), 'Strategic Environmental Policy and International Trade', Journal of Public Economics 54, 325-338.

Brander, J. A. and P. Krugman (1983), 'A "Reciprocal Dumping” Model of International Trade', Journal of International Economics 15, 313-321.

Brander, J. A. and B. J. Spencer (1985), 'Export Subsidies and International Market Share Rivalry', Journal of International Economics 18, 83-100.

Buchholz, W. and K. A. Konrad (1994), 'Global Environmental Problems and the Strategic Choice of Technology', Journal of Economics 60, 299-321.

Burguet, R. and J. Sempere (2003), 'Trade Liberalization, Environmental Policy, and Welfare', Journal of Environmental Economics and Management 46, 25-37.

Conrad, K. (1993), 'Taxes and Subsidies for Pollution-Intensive Industries as Trade Policy', Journal of Environmental Economics and Management 25, 121-135. 
Copeland, B. R. and M. S. Taylor (1994), 'North-South Trade and the Environment', Quarterly Journal of Economics 109, 755-787.

Copeland, B. R. and M. S. Taylor (1995), 'Trade and Transboundary Pollution', American Economic Review 85, 717-737.

Dixit, A. (1984), 'International Trade Policy for Oligopolistic Industries', Economic Journal (Conference Supplement) 94, 1-16.

Duval, Y. and S. Hamilton (2002), 'Strategic Environmental Policy and International Trade in Asymmetric Oligopoly Markets', International Tax and Public Finance 9, 259-271.

Eaton, J. and G. M. Grossman (1986), 'Optimal Trade Policy and Industrial Policy Under Oligopoly', Quarterly Journal of Economics 101, 383-406.

Elbers, C. and C. Withagen (2002a), 'Environmental Policy and Bertrand Competition: A General Equilibrium Approach', in C. Hommes, R. Ramer and C. Withagen, eds., Equilibrium, Markets and Dynamics. Essays in Honor of Claus Weddepohl. Berlin: Springer.

Elbers, C. and C. Withagen (2002b), 'Environmental Regulation and International Trade: A General Equilibrium Approach', in J. List and A. Zeeuwde, eds., Recent Advances in Environmental Economics. Cheltenham, UK and Northampton, Mass: Edward Elgar.

Greaker, M. (2003), 'Strategic Environmental Policy; Eco-dumping or a Green Strategy?', Journal of Environmental Economics and Management 45, 692-707.

Hoel, M. (1997), 'Environmental Policy with Endogenous Plant Locations', Scandinavian Journal of Economics 99, 241-259.

Kennedy, P. W. (1994), 'Equilibrium Pollution Taxes in Open Economies with Imperfect Competition', Journal of Environmental Economics and Management 27, 49-63.

Markusen, J. R., E. R. Morey and N. Olewiler (1993), 'Environmental Policy When Market Structure and Plant Locations are Endogenous', Journal of Environmental Economics and Management 24, 69-86.

Markusen, J. R., E. R. Morey and N.Olewiler (1995), 'Competition in Regional Environmental Policies When Plant Locations are Endogenous', Journal of Public Economics 56, 55-78.

Naylor, R. A. (1998), 'International Trade and Economic Integration when Labour Markets are Generally Unionised', European Economic Review 42, 1251-1267.

Naylor, R. A. (1999), 'Union Wage Strategies and International Trade', Economic Journal 109, 102-125.

Neary, P. J. (2006), 'International Trade and the Environment: Theoretical and Policy Linkages', Environmental and Resource Economics 33, 95-118.

Pflüger, M. (2001), 'Ecological Dumping Under Monopolistic Competition', Scandinavian Journal of Economics 103, 689-706.

Rauscher, M. (1994), 'On Ecological Dumping', Oxford Economic Papers 46, 822-840.

Singh, N. and X. Vives (1984), 'Price and Quantity Competition in a Differentiated Duopoly', RAND Journal of Economics 15, 546-554.

Tanguay, G. A. (2001), 'Strategic Environmental Policies Under International Duopolistic Competition', International Tax and Public Finance 8, 793-811.

Ulph, A. (1996), 'Environmental Policy and International Trade When Governments and Producers Act Strategically', Journal of Environmental Economics and Management 30, 265-281.

Ulph, A. and L. Valentini (2001), 'Is Environmental Dumping Greater When Plants Are Footloose?', Scandinavian Journal of Economics 103, 673-688.

Walz, U. and D. Wellisch (1997), 'Is free trade in the interest of exporting countries when there is ecological dumping?', Journal of Public Economics 66, 275-291. 
WTO (1999), Trade and environment, Special Studies 4, World Trade Organization, WTO Publications, Geneva. (Available from http://www.wto.org).

\section{Appendix}

\section{A. SOCIAL WELFARE COMPONENTS AS FUNCTIONS OF EMISSION TAX RATES}

Social welfare in country $i$ is defined by (11). Inserting the equilibrium expressions from the product market subgame, given by (8)-(10), we derive the following expressions for the different welfare components as functions of emission tax rates:

$$
\begin{aligned}
& U^{i}\left(\tau_{i}, \tau_{j}\right)=\frac{2(2-b)^{2}\left(3+b-t-\tau_{i}-\tau_{j}\right)-\gamma\left(\tau_{i}^{2}+\tau_{j}^{2}+t\left(2 \tau_{j}+t\right)\right)-2 b^{3} \tau_{i}\left(t+\tau_{j}\right)}{2\left(4-b^{2}\right)^{2}}, \\
& S^{i}\left(\tau_{i}, \tau_{j}\right)=\frac{(2-b)\left[\left(\tau_{j}-\tau_{i}\right)\left(b+\tau_{i}+\tau_{j}\right)-2 t^{2}\right]-t\left[\left(1-\tau_{i}\right) b^{2}+4(1-b)\left(1-\tau_{j}\right)\right]}{(2-b)^{2}(2+b)}, \\
& -D^{i}\left(\tau_{i}, \tau_{j}\right):=-D^{i}\left(\Omega^{i}\left(\tau_{i}, \tau_{j}\right)\right),
\end{aligned}
$$

where

$$
\begin{aligned}
& \Omega^{i}\left(\tau_{i}, \tau_{j}\right)=\frac{\left(\tau_{i}+\alpha \tau_{j}\right)\left(4(1+c)-b^{2}\right)-2 c b\left(\alpha \tau_{i}+\tau_{j}\right)-(2-b)(2-t)(1+\alpha) c}{\left(4-b^{2}\right) c} \\
& -c^{i}\left(\tau_{i}, \tau_{j}\right)=-\frac{\tau_{i}^{2}}{2 c}
\end{aligned}
$$

\section{B. PROOF OF PROPOSITION 2}

Policy coordination yields higher emission taxes, and thus reduces pollution, if

$$
\frac{\partial W^{j}\left(\tau_{n c}\right)}{\partial \tau_{i}}=\frac{\partial U^{j}\left(\tau_{n c}\right)}{\partial \tau_{i}}+\frac{\partial S^{j}\left(\tau_{n c}\right)}{\partial \tau_{i}}-\frac{\partial D^{j}\left(\tau_{n c}\right)}{\partial \tau_{i}}-\frac{\partial C^{j}\left(\tau_{n c}\right)}{\partial \tau_{i}}>0 .
$$

We know that $\frac{\partial C^{i}\left(\tau_{n c}\right)}{\partial \tau_{i}}=0$. From (33) and (34) we derive

$$
\begin{aligned}
& \frac{\partial U^{j}\left(\tau_{n c}\right)}{\partial \tau_{i}}+\frac{\partial S^{j}\left(\tau_{n c}\right)}{\partial \tau_{i}}= \\
& \frac{4(1-b) t+(2-b)\left(3 b+b^{2}-2\right)+\tau_{n c}(2-b)\left(2+b+b^{2}\right)-b^{2} t}{(2+b)^{2}(2-b)^{2}}
\end{aligned}
$$


Under the assumption that $\tau_{n c} \geq 0$, a sufficient condition for this expression to be positive is $b>\frac{1}{2} \sqrt{17}-\frac{3}{2} \approx 0.56$. Finally, from (35) we have that

$$
-\frac{\partial D^{j}\left(\tau_{n c}\right)}{\partial \tau_{i}}>0 \text { iff } \alpha>\widehat{\alpha}:=\frac{2 b c}{4 c+(b+2)(2-b)} .
$$

Thus, sufficient conditions for $\frac{\partial W^{j}\left(\tau_{n c}\right)}{\partial \tau_{i}}>0$ are $b>\frac{1}{2} \sqrt{17}-\frac{3}{2}$ and $\alpha>\widehat{\alpha}$. QED.

\section{PROOF OF PROPOSITION 3}

(i) Setting $D^{\prime \prime}(\cdot)=0$ in (39), (41) and (43), we have that

$$
\frac{\partial^{2} W^{j}\left(\tau_{n c}\right)}{\partial t \partial \tau_{i}}=\frac{(1-b)(4+3 c)-b^{2}}{(2-b)\left[(2-b)(2+b)^{2}+c\left(6+3 b-b^{2}\right)\right]}
$$

This sign of this expression depends on the sign of the numerator, and we see that

$$
\frac{\partial^{2} W^{j}\left(\tau_{n c}\right)}{\partial t \partial \tau_{i}}>0 \text { iff } b<\bar{b}:=\frac{1}{2}(\sqrt{(3 c+8)(3 c+4)}-4-3 c) .
$$

Since $\frac{\partial \bar{b}}{\partial c}>0$ for $c \geq 0, \lim _{c \rightarrow 0} \bar{b}=2(\sqrt{2}-1) \approx 0.83$, and $\lim _{c \rightarrow \infty} \bar{b}=1$, we can conclude that $\bar{b} \in(0.83,1)$. (ii) From (20) and (32) we derive

$$
\frac{\partial\left(\tilde{\tau}_{c}-\tilde{\tau}_{n c}\right)}{\partial t}=\frac{\left[c\left[(4+3 c)(1-b)-b^{2}\right]+d(1+\alpha) \Psi\right](2+b)^{2} c^{2}}{\left[d(2+b+2 c)^{2}(1+\alpha)^{2}+c\left(2 c(1+b)+(2+b)^{2}\right)\right] \Omega(2-b)}
$$

where

$$
\begin{aligned}
\Psi:= & c(1-b)(6+b+2 c)-\alpha c\left(14-5 b+b^{2}-2 b c+6 c\right) \\
& -b(4+b)+4(1+b \alpha)-\alpha\left(4-2 b+b^{2}\right)(2+b), \\
\Omega:= & d(2+b+2 c)(1+\alpha)\left(4+2 c(2-b \alpha)-b^{2}\right) \\
& +c\left(8+2 b(2-b)+3 c(2+b)-b^{2}(b+c)\right) .
\end{aligned}
$$

Since $\Omega>0$, the sign of $\frac{\partial\left(\tilde{\tau}_{c}-\tilde{\tau}_{n c}\right)}{\partial t}$ is determined by the sign of the numerator in $(\mathrm{C} 2)$. Define $\Theta:=c\left[(4+3 c)(1-b)-b^{2}\right]+d(1+\alpha) \Psi$. Then $\operatorname{sign}\left(\frac{\partial\left(\tilde{\tau}_{c}-\tilde{\tau}_{n c}\right)}{\partial t}\right)=\operatorname{sign} \Theta$. It is easily verified that $\Theta$ is monotonically decreasing in both $\alpha$ and $b$. Now assume that $b=1$. Then we have that

$$
\Theta=-[c+d+\alpha d(6+5 \alpha+2 c(5+2 c)(1+\alpha))]<0
$$

Thus, $\frac{\partial\left(\tilde{\tau}_{c}-\tilde{\tau}_{n c}\right)}{\partial t}<0$ if $b$ is sufficiently high. Now assume that $b=0$. In this case we have

$$
\Theta=c(4+3 c)+2 d(2+3 c)-2 \alpha d(c+1)[2(1+c)+\alpha(4+3 c)]
$$

which is positive if

$$
\alpha<\tilde{\alpha}:=\frac{\sqrt{2} \sqrt{d(1+c)\left(c(4+3 c)^{2}+2 d(1+c)(3+2 c)^{2}\right)}-2 d(1+c)^{2}}{6 d\left(\frac{4}{3}+c\right)(1+c)} .
$$


It is possible to show that $\tilde{\alpha} \geq \frac{1}{3}$ for all $c \geq 0$ and $d \geq 0$. This suggests that $\frac{\partial\left(\tilde{\tau}_{c}-\tilde{\tau}_{n c}\right)}{\partial t}>0$ if both $b$ and $\alpha$ are sufficiently small. We can finally confirm this by setting $\alpha=b=0$. In this case, we have that

$$
\Theta=4 c+4 d+6 c d+3 c^{2}+2 c^{2} d>0 .
$$

QED.

\section{PROOF OF PROPOSITION 4}

From (44) we derive

$$
\frac{\partial\left[W^{i}\left(\bar{\tau}_{c}\right)-W^{i}\left(\bar{\tau}_{n c}\right)\right]}{\partial t}=-\frac{(2+b)^{2} \Phi\left[(4+3 c)(1-b)-b^{2}\right]}{(2-b)^{2} \beta^{2}\left[(2+b)^{2}+2 c(1+b)\right]},
$$

where $\Phi \lessgtr 0$ and $\beta>0$ have been defined in Section 5. Thus, sufficient conditions for $\frac{\partial\left[W^{i}\left(\bar{\tau}_{c}\right)-W^{i}\left(\bar{\tau}_{n c}\right)\right]}{\partial t}>0$ are $\Phi>0$ and $(4+3 c)(1-b)-b^{2}>0$. The latter condition can be expressed as $b<\bar{b}$, where $\bar{b}$ is defined in Proposition 3, while $\Phi>0$ iff $\alpha>\bar{\alpha}$, where $\bar{\alpha}$ is defined by (37). From the definition of $\bar{\alpha}$ it follows that $\bar{\tau}_{c}>\bar{\tau}_{n c}$ iff $\alpha>\bar{\alpha}$. QED. 